\title{
MANAJEMEN KEPEMIMPINAN KIAI DAN KONTRIBUSINYA TERHADAP MUTU PENDIDIKAN PESANTREN
}

\author{
Zainuddin Syarif \\ Sekolah Tinggi Agama Islam Negeri (STAIN) Pamekasan \\ doktorzainuddinsyarif@gmail.com
}

\begin{abstract}
Abstrac
Pesantren is the most important part of some education in Indonesia, it is the oldest institution of Islamic education in Indonesia and is also part of indegenous culture. Pondok Pesantren has a religious purpose, according to founder kiai, the habit of establishing pesantren is influenced by personal experience of kiai during studying in pesantren.Tulisan try to analyze about management aspect in leadership of a kiai in pesantren and its contribution to quality of pesantren education, kiai has been able to strengthen existence pesantren institutions are mostly successful in producing santri who are mah-mahmah and qualified in religious matters, but are less able to respond and accommodate to the needs of the times.
\end{abstract}

Keywords: Leadership Management, Kiai and Pesantren

\begin{abstract}
Abstrak
Pesantren adalah bagian terpenting dari beberapa pendidikan di Indonesia, institusi ini merupakan institusi pendidikan Islam paling tua di Indonesia dan juga merupakan bagian dari budaya indigenous bangsa (indegenous culture). Pondok Pesantren memiliki tujuan keagamaan, menurut orang kiai pendiri, kebiasaan mendirikan pesantren dipengaruhi oleh pengalaman pribadi kiai selama belajar di pesantren. Tulisan ini mencoba mengurai tentang aspek manajemen dalam kepemimpinan seorang kiai di pesantren serta peran kontribusinya terhadap mutu pendidikan pesantren, kiai telah mampu menguatkan eksistensi lembaga pesantren sebagian besar berhasil dalam menghasilkan santri yang berakhlakul-karimah dan mumpuni dalam masalah agama, tetapi kurang mampu merespon dan akomodatif terhadap kebutuhan zaman.
\end{abstract}

Kata Kunci: Manajeman Kepemimpinan, Kiai dan Pesantren 
Zainuddin Syarif, Manajemen Kepemimpinan Kiai dan Kontribusinya Terhadap Mutu Pendidikan Pesantren

\section{Pendahuluan}

Bermacam varian gaya masing-masing individu dalam kepemimpinan, (termasuk kepemimpinan kiai) dan mempunyai dampak yang signifikan terhadap kehidupan para santri-santrinya. Ciri khas santri sangat erat dengan proses interaksi dan komunikasi yang terjadi antara pimpinan (top up) dan bawahan (top down) yang dipengaruhi oleh efektifitas pimpinan. Proses dari formulasi kebijakan menurut teori ini, elit secara top down membuat kebijakan publik untuk diimplementasikan oleh administratur publik kepada rakyat atau masyarakat ${ }^{1}$.

Bagi santri agar tunduk patuh sesuai undang-undang pondok pesantren tidak lain merupakan anjuran sang kiai, maka figur seorang kiai dalam membangkitkan para santri-santrinya adalah hal utama dalam menggerakkan dan memajukan lembaga pendidikan islam berupa pondok pesantren. Masalah yang timbul yaitu bagaimana santri diarahkan supaya dapat sesuai dengan apa yang dicita-citakan oleh pesantren.

Setiap lembaga pendidikan baik besar maupun kecil pasti mempunyai berbagai tujuan yang hendak dicapai, dan tujuan tersebut memerlukan proses pengaturan melalui manajemen. Pondok pesantren sebagai lembaga/organisasi pendidikan yang terdiri dari beberapa kumpulan orang seperti: kyai sebagai pimpinan atau pengasuh, pengurus pesantren, asatidz (dewan guru), dan santri merupakan satu kesatuan yang terlibat dalam melakukan aktivitas-aktivitas pendidikan. Kehadiran madrasah/sekolah dan lembaga-lembaga lainnya seperti keterampilan dan kursus dalam lingkungan pesantren sebagai usaha untuk merespon perkembangan ilmu pengetahuan dan teknologi tentunya membutuhkan pengelolaan atau manajemen yang pada akhirnya akan terbentuk model atau sistem dari pendidikan pesantren.

Kiai merupakan figur sentral yang memiliki banyak peran, mulai dari sebagai pemimpin, pondok sementara, guru dan mentor hingga siswa, suami, dan ayah di keluarga mereka sendiri yang juga menetap di pondok. Posisi kiai sebagai pemimpin pesantren juga diharuskan untuk menjunjung tinggi nilai-nilai luhur yang menjadi acuan dalam bertingkah laku dan pengembangan pesantren. Ajaran luhur yang menjadi sebuah kepercayaan kiai dalam hidupnya maka ketika dalam memimpin di pesantren tidak bertentangan atau menyimpang dari nilai-nilai mulia yang beliau percaya sejak awal,

\footnotetext{
${ }^{1}$ Ismail, "Politik Pendidikan Islam di Daerah (Studi Kebijakan Pemerintah Provinsi Jawa Timur Dalam Pengembangan Madrasah Diniah)", (Ph. D. Diss., Pascasarjana Universitas Islam Negeri Sunan Ampel Surabaya), 2017.
} 
baik kepercayaan langsung maupun tidak langsung masyarakat terhadap kiai atau pesantren akan memudar. Karena sebenarnya nilai-nilai luhur yang diyakini oleh kiai atau kaum muslimin menjadi kekuatan yang diyakini sebagai rahmat Allah SWT.

Dalam penelitian Guntur Cahaya Kesuma, sosok kyai bisa memiliki dua atau tiga karakteristik secara bersamaan, misalnya gabungan antara karismatik-rasional, dan tradsional-rasional, atau kharismatik-tradsional-rasional. Lebih lanjut Imron Arifin Pesantren adalah lembaga pendidikan yang tidak bisa dipisahkan dari sosok seorang kyai sebagai pemimpinnya. Kemajuan atau kemunduran pesantren banyak ditentukan oleh sosok kyai sebagai figur sentral di pesantren. Dengan demikian, pesantren dan kyai mempunyai hubungan yang saling mempengaruhi. Pesantren bisa berkembang karena sosok kyainya yang bisa memimpin dengan baik. Sebaliknya, pesantren tidak berkembang karena sosok kyainya yang tidak bisa memimpin dengan baik. ${ }^{2}$

\section{Manajeman Budaya Organisasi Pesantren}

Manajemen pada dasarnya mengandung tiga indera. Pertama, manajemen bagian dari sebuah proses meneuju kemapanan berfikir. Kedua, manajemen sebagai kolektifitas orang yang sedang melakukan kegiatan dalam pengelolaan. Ketiga, manajemen adalah sebagai seni dan bagian dari ilmu pengetahuan. Manajemen sebagai sebuah proses, Johnson dalam The Theory and Management of System seperti dikutip Made Pidarta, mengatakan bahwa manajemen adalah proses mengintegrasikan sumber yang tidak terkait ke dalam keseluruhan system untuk menyelesaikan sebuah tujuan. ${ }^{3}$ Selanjutnya Made Pidarta menjelaskan bahwa apa yang dimaksud dengan sumber adalah dengan memasukkan orang, alat, media, bahan, uang, dan sarana yang semuanya diarahkan dan dikoordinasikan untuk dipusatkan agar tercapai tujuannya. ${ }^{4}$

Manajemen sebagai kolektivitas orang yang melakukan aktivitas adalah "semua orang melakukan kegiatan pengelolaan di tubuh yang ditentukan,"5 atau dengan kata lain orang-orang yang terlibat dalam satu kesatuan aktivitas. Pengertian yang terakhir dari manajemen adalah sebagai seni berfungsi untuk mencapai tujuan nyata dan membawa hasil atau keuntungan, sedangkan manajemen sebagai fungsi sains untuk

\footnotetext{
${ }^{2}$ Guntur Cahaya Kesuma, Pesantren dan Kepemimpinan Kyai. Terampil. Jurnal Pendidikan dan Pembelajaran Dasar, Vol, 1. No, 12014

${ }^{3}$ Made Pidarta, Manajemen Pendidikan Indonesia, (Jakarta: Bina Aksara, 1988). 3

${ }^{4}$ Ibid.., 23

${ }^{5}$ Permadi, Pemimpindan Kepemimpinan dalam Manajemen (Jakarta: RinekaCipta, 1996). 23
} 
Zainuddin Syarif, Manajemen Kepemimpinan Kiai dan Kontribusinya Terhadap Mutu Pendidikan Pesantren

menjelaskan fenomena (fenomena), kejadian, keadaan. ${ }^{6}$ Budaya organisasi memiliki beberapa fungsi, yaitu menetapkan tapal batas, memberikan rasa identitas pada anggota organisasi.

Karakteristik budaya organisasi tersebut merupakan nilai-nilai yang menjadi pedoman para karyawan dalam perilaku kerja mereka.Para karyawan dituntut untuk lebih inovatif, mengambil resiko, memperhatikan rincian pekerjaan dan berorientasi pada pencapaian hasil. Pihak manajemen dalam dalam membuat keputusan harus memperhatikan kepentingan para karyawan dan kerjasama tim. Seluruh anggota organisasi dituntut untuk bersikap dinamis dalam mencapai pertumbuhan tanpa mengabaikan perlunya stabilitas dalam pekerjaan.

Budaya organisasi memiliki peranan penting dalam menjaga stabilitas sistem sosial karena mampu membentuk sikap dan perilaku bawahan. Budaya organisasi dengan ini juga meningkatkan para bawahan terhadap pencapaian tujuan organisasi sehingga disamping menggambarkan identitas organisasi, budaya organisasi juga memberikan batasan nilai-nilai organisasi yang dimiliki yang berbeda dengan budaya organisasi yang lain.

Dalam konteks pesantren, masih relatif kecil (start up organization) bahwa memiliki asumsi biasanya berdasar pada para leluhur the founding father (pendiri dari pesantren). Dasar asumsi tersebut dimiliki oleh mayoritas penghuni pesantren sebagai standarisasi pandangan segala tindakan, yaitu: perasaan bersama (penyatuan emosi atau psikis), perbuatan bersama, ucapan bersama (bahasa bersama), dan hal-hal bersama (memahami benda dengan sudut pandang yang sama), dengan ini menciptakan sebuah budaya. Ilustrasi proses pembentukan budaya. ${ }^{7}$ David Mc Clelland yang dikenal dengan Three Needs Theory, menyebutkan tiga jenis kebutuhan yaitu: 1) Perlu pencapaian dorongan untuk berprestasi, untuk mencapai kaitannya dengan aset standar, untuk mencapai kesuksesan; 2) Membutuhkan kekuatan keinginan untuk membuat orang lain berperilaku tidak sadar sehingga mereka tidak berperilaku sebaliknya; 3) Perlu berafiliasi-keinginan untuk hubungan interpersonal yang bersahabat dan dekat. ${ }^{8}$

\footnotetext{
${ }^{6} \mathrm{Ibid}, . .24$

${ }^{7}$ Vijay Shate, Culture and Related Corporate Realistics, (Homewood: Illinois: Ricard D. Irwin, Inc, 1982), 234

${ }^{8}$ Stephen P. Robbins and Timoty A. Judge, Organizational Behavior. 2007. New Jersey: Pearson Interntional Education. 192
} 


\section{Jaringan Kepemimpinan Kiai ${ }^{9}$}

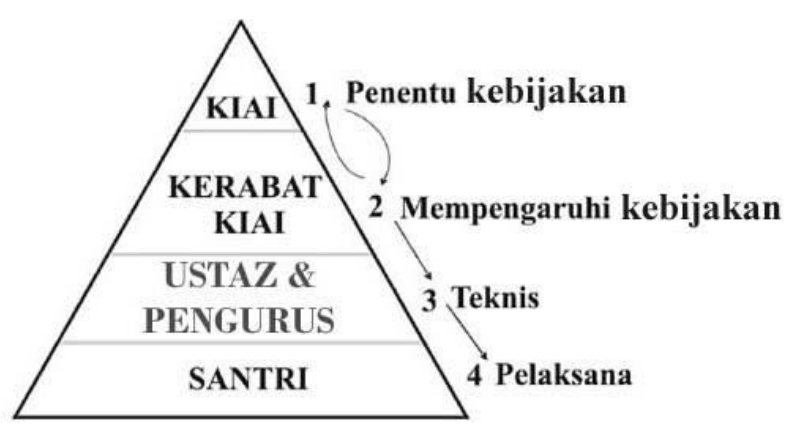

Dari gambaran jaringan kekuasaan kiai tersebut dapat dikatakan bahwa simpul utamanya berpijak pada pesantren yang disempurnakan oleh kekuatan santri dan dukungan masyarakat para pembuat kebijakan harus mulai dengan mempertimbangkan instrumen kebijakan dan sumber daya yang tersedia untuk perubahan kebijakan (pemetaan maju). Selain itu, mereka hasu mengetahui struktur insentif pelaksana dan kelompok sasaran (pemetaan mundur) ${ }^{10}$. Dengan kata lain, masing-masing pesantren merupakan singgasana bagi elit kiai yang mempunyai kekuasaan tersendiri di masingmasing wilayahnya. Melihat fakta tersebut, Zamakhsyari Dhofier mengibaratkan pesantren sebagai suatu kerajaan kecil. Kiai merupakan sumber mutlak dari kekuasaan dan kewenangan dalam kehidupan di lingkungan pesantren ${ }^{11}$. Kiai dengan singgasana pesantrennya selalu berusaha membangun kekuatan yang harmonis dengan jaringan kekuasaannya yang berada di luar Pesantren.

Menurut Harrison dan Carrol, ada tiga kekuatan yang memainkan peran sangat penting dalam menjaga budaya, termasuk budaya pesantren, yaitu: seleksi, manajemen puncak, dan metode sosialisasi. Adapun tujuannya adalah untuk mengidentifikasi mempekerjakan orang-orang yang memiliki wawasan keilmuan, etika dan kemampuan estetika. Manajemen kepemimpinan dalam organisasi memiliki dampak yang besar pada proses kultur dalam sebuah organisasi, bagaimana pimpinan berperilaku dan bagaimana menegakkan norma-norma dan nilai-nilai pada bawahan sepanjang organisasi, misalnya apakah pengambilan resiko diinginkan, berapa banyak kebebasan seharusnya diberikan

\footnotetext{
${ }^{9}$ Zainuddin Syarif, DinamikaPolitikKiaidanSantridalamPilkadaPamekasan. (Surabaya: Desertasi:IAIN Sunan Ampel, 2010), 50

${ }^{10}$ Ismail, PolitikPendidikan Islam di Daerah.., 77-78.

${ }^{11}$ Zamahsyari Dhofier, Tradisi Pesantren; Studi tentang Pandangan Hidup Kiai (Jakarta: LP3ES,1982),. 56.
} 
Zainuddin Syarif, Manajemen Kepemimpinan Kiai dan Kontribusinya Terhadap Mutu Pendidikan Pesantren

pada bawahan oleh para manager, pakaian apakah yang pantas, dan tindakan apakah akan diimbali dalam kenaikan upah, promosi, dan ganjaran lainnya. Sosialisasi,ialah proses yang mengadaptasikan para karyawan pada budaya organisasi. Sosialisasi dilakukan dalam tiga tahap, yaitu: tahap prakedatangan, perjumpaan, dan metamorfosis. $^{12}$

\section{Pola Kepemimpinan Kiai}

Dalam budaya pesanten, seorang kiai dianggap memiliki berbagai peran, baik sebagai pemimpin, penjaga kustodian, guru dan mentor untuk siswa dan suami dan ayah di keluarga mereka sendiri yang juga menetap di pondok. Posisi kiai sebagai pemimpin pesantren juga diharuskan untuk menjunjung tinggi nilai-nilai luhur yang menjadi acuan dalam perilaku dan pengembangan pesantren. ${ }^{13}$ Posisi Kiai salah satu elemen terpenting di pesantren, dia adalah sosok yang disegani, maka tidak heran jika kiai memiliki beberapa kemampuan dan kedudukan, antara lain: beliau sebagai arsitektur, pendiri dan pengembang, dan juga pemimpin dan manajer (pemimpin dan manajer). ${ }^{14}$

Pola kepemiminan kiai lebih dekat dengan kepemimpinan transaksional dan transformasional,ditandai dari salah satu gaya kepemimpinan yang pada dasarnya menekankan transaksi antara pemimpin dan bawahan. Kepemimpinan transaksional menekankan proses hubungan pertukaran yang layak secara ekonomi untuk memenuhi kebutuhan psikologis sesuai dengan kontrak yang telah mereka sepakati.

Seorang kiai adalah pemimpin diyakini mampu mengubah lingkungan kerja, motivasi kerja, pola kerja, dan nilai kerja yang dirasakan bawahan sehingga mereka lebih mampu mengoptimalkan kinerja untuk mencapai tujuan organisasi. Karakteristik kepemimpinan kiai yang efektif menurut Dubin, yaitu mampu memenuhi tiga hal, ialah (a) create an atmosphere conducive for student learning (menciptakan iklim yang kondusif bagi murid untuk belajar); (b) teacher involvement and growt (para guru terlibat dan bertumbuh); (c) community support and high expectations (semua

\footnotetext{
${ }^{12}$ R. Harrison dan G.R. Carrol, Keeping The Faith: A Model of Cultural Transmission in Forma Organizations, Administrative Science Quartely, Desember 1991.

${ }^{13}$ Nurcholis Majid, Bilik-Bilik Pesantren: Sebuah Potret Perjalanan, (Jakarta: Paramadina, 1995), 465

${ }^{14}$ Azyumardi Azra, Pendidikan Islam: Tradisidan Modernisasi Menujumillenium Baru, (Jakarta: Logos Wacanallmu, 2000), 45
} 
masyarakat memberikan dorongan dan memmpunyai harapan besar). ${ }^{15}$ Berikut kira-kira gambaran kepemimpinan kiai di dalam pesantren:

\section{Gambaran Kepemimpinan Kiai ${ }^{16}$}

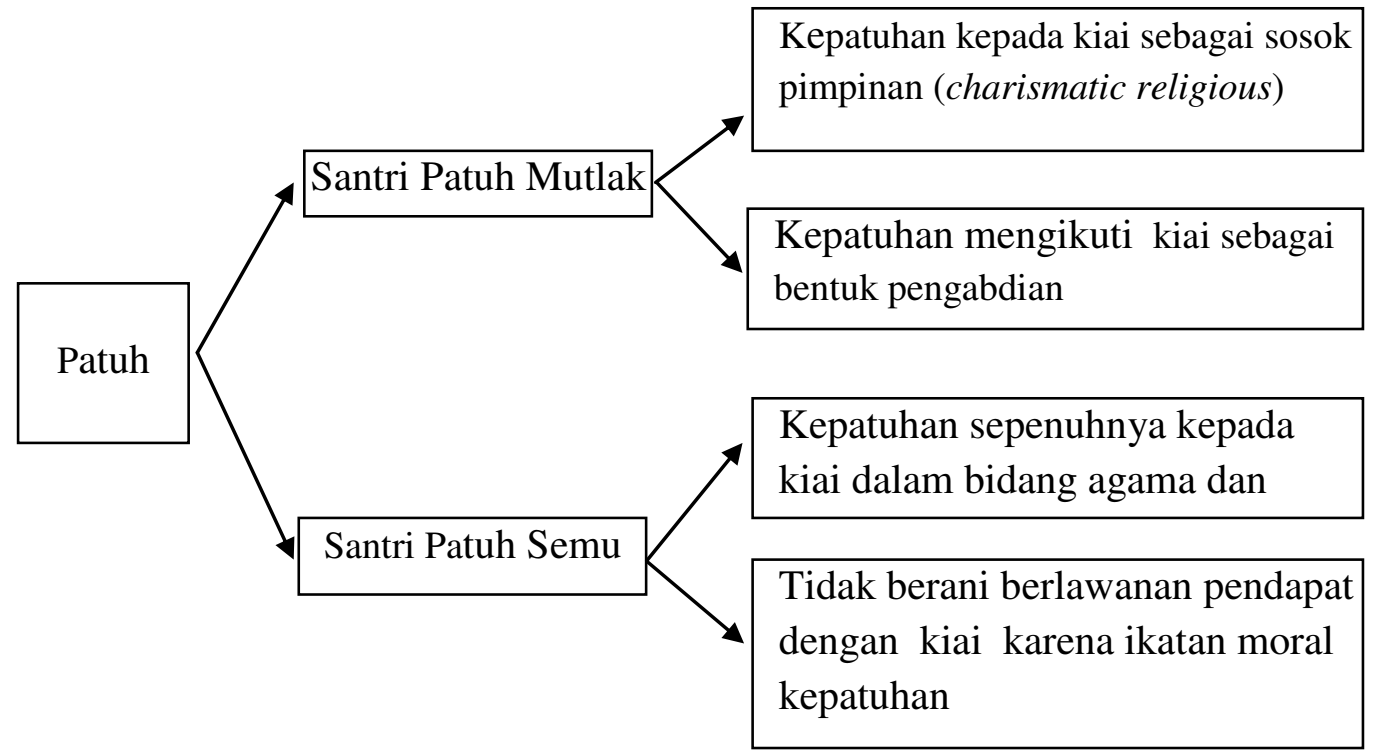

Gambar di atas menunjukkan bahwa santri patuh mutlak adalah santri yang selalu patuh dan taat kepada orang yang jadi panutannya. Begitu dominannya, peran kiai terhadap santri, salah satunya dapat digambarkan dengan sikap ketawaduannya (sam'an wa thã 'atan) pada perintah kiai yang dianggap merupakan sebuah kebenaran yang harus diikuti. ${ }^{17}$ Kiai memiliki peran polymorphic, yakni sebagai "sumber dan rujukan dasar" yang kuat, yang diasumsikan dapat mengatasi semua persolan yang terjadi dalam masyarakat.

Pengetahuan dipandang tidak hanya merupakan corpus pengakuan yang baku, tetapi otentisitasnya juga dibuat tergantung pada kata-kata sejumlah orang besar tertentu, yang otoritasnya harus diakui, setidak-tidaknya oleh santri. Apa yang diucapkan oleh ulama (kiai) harus diterima sepenuhnya karena dipandang sebagai kebenaran mutlak. ${ }^{18}$ Pola hubungan kiai-santri berlangsung tertutup. Hanya ada hubungan dua pihak secara vertikal. Dalam istilah antropologi, pola hubungan tersebut

\footnotetext{
${ }^{15}$ A.E. Dubin, The Principal as Chief Executive Officer (London: The Falmer Press, 1991), .. 49

${ }^{16}$ Model ini dibuat oleh Zainuddin Syarif, Dinamika Politik Kiai dan Santri dalam Pilkada Pamekasan.., 63

${ }^{17}$ Sukamto, Kepemimpinan Kiai dalam Pesantren, (Jakarta: Pustaka LP3ES, 1999)

${ }^{18}$ Syafiq A. Mughni, Dinamika Intelektual Islam; Pada Abad Kegelapan (Surabaya: LPAM, 2002), 23
} 
Zainuddin Syarif, Manajemen Kepemimpinan Kiai dan Kontribusinya Terhadap Mutu Pendidikan Pesantren

dikenal dengan dyadic-vertical. ${ }^{19}$ Begitu tertutupnya hubungan itu sehingga, mengakibatkan unsur-unsur lain diseleksi begitu ketat dan terkesan tidak dapat menerima sesuatu dari luar. Sementara dalam istilah sosiologi, dikenal adanya masyarakat paguyuban. Semua orang akan guyub mengikuti apa-apa yang sudah menjadi ketentuan bersama.

\section{Mutu Pendidikan Pesantren}

Pesantren sebagai lembaga pendidikan yang menjadi bagian penting sistem pendidikan nasional perlu memiliki standar mutu yang jelas. Maka standar mutu pendidikan pesantren yang bermutu adalah yang dapat memenuhi standar pendidikan nasional sebagaimana yang termaktub dalam UU No. 20/2003 dan PP No. 13/2015, sebagaimana yang mencakup delapan standar.

Mutu pendidikan pesantren merupakan ukuran terhadap sesuatu yang diharapkan tercapai dan suatu produk atau layanan bagi para pelanggan yang ada. Pesantren yang bermutu adalah yang memiliki standar yang jelas dan telah disepakati bersama. Dengan demikian, pendidikan pesantren dikatakan bermutu bila orientasi mutu pendidikan yang terdiri dari input, proses dan output dapat terpenuhi dengan baik.

Kepemimpinan kiai sangat memberikan kontribusi tersendiri bagi keberhasilan pengembangan mutu pesantren, karena menawarkan paradigma yang berbeda dalam mengembangkan konsep character building, kiai berhasil mampu meningkatkan kualitas pendidikan. ${ }^{20}$ Model kepemimpinan kiai akan berpengaruh pada pendidikan yang dikembangkan oleh pesantren dan menawarkan perspektif alternatif dalam pengembangan pendidikan karakter di Indonesia.

Orientasi mutu pendidikan juga diimplementasikan dengan mengembangkan dan mengaktualisasikan segenap potensi peserta didik secara optimal dalam rangka pemberdayaan seluruh masyarakat. Peserta didik (santri) akan mampu terlibat secara aktif, kreatif, inovatif dan efektif dalam berbagai bidang kehidupan masyarakat sesuai dengan kebutuhan dan perkembangan Iptek dan masyarakat.

Di antara beberapa keistemewaan pendidikan pesantren. Pertama, kiai dan para ustazd telah menjalankan fungsinya sebagai guru dengan meperlakukan santri secara

\footnotetext{
${ }^{19}$ Suhardi Sigit, Prilaku Organisasional Common Understanding (Yogyakarta: BPFE-UTS, 2003)

${ }^{20}$ Hasan Baharun, Total Moral Quality: A New Approach For Character Education In Pesantren “ Ulumuna Journal of Islamic Studies. Volume. 21, Nomor. 1, 2017, 57-80
} 
humanis dengan mengembangkan individu dalam rangka menerapkan dan meraih tanggung jawab. Kiai dan para ustazd selalu memberikan contoh yang baik kepada santri dan mengkondisikan agar santri senantiasa menjadi pribadi yang memeperbaiki dirinya setiap saat. Kedua, di antara metode pembelajaran yang digunakan: (1) Sorogan, (2) Wetonan atau bandungan, (3) Halaqoh, (4) Hafalan atau tahfizh, (5) Hiwar atau musyawarah, (6) Bahtsul masa'il (Mudzakaroh), (7) Fathul Kutub, (8) Muqoronah dan (9) Muhawarah / Muhadatsah.

Ketiga, santri telah mampu memiliki kesadaran tentang pentingnya mencari ilmu untuk bekal kehidupan di masa yang akan datang. Dari kesadaran tersebut menyebabkan mereka bersemangat dalam menjalani proses belajar mengajar di Pondok pesantren. Keempat, sistem Pembelajaran 24 jam (Boarding School). Kelebihan dari pesantren di bawah kepemimpinan kiai, yaitu adanya sistem pembelajaran 24 jam (boarding school), sehingga seluruh santri setelah belajar secara teori di kelas (sekolah) mereka mengimplementasi-kannya dalam kehidupan sehari-hari. Dalam proses pembelajaran 24 jam tersebut, santri-santri sangat terorganisir dalam melakukan aktivitasnya, sehingga sangat mudah mengontrol para santri yang begitu banyak dan heterogennya dalam melakukan kegiatan intra maupuan ekstra kurikuler.

\section{Penutup}

Kepemimpinan kiai di pesantren adalah terbentuk dalam jaringan makna personal, sosial komunitas santri melalui berbagai ragam kreatifitas dan kearifan lokal. Begitu dominannya peran kiai terhadap santri, sehingga sikap ketawaduannya (santri kepada kiai) sangat luar biasa. Santri memandang kiai serba bisa dalam berbagai hal (polymorphic) dan menjadi sumber rujukan dalam perilaku kehidupan sehari-hari santri. Di bawah kepemimpinan seorang kiai, pesantren mampu menghasilkan out put berupa generasi-generasi muda yang mampu memahami jati dirinya sebagai manusia.

Sesuai dengan penekanan pendidikan pesantren adalah usaha sadar untuk mengantarkan santri memiliki hubungan yang sangat kuat antara jiwa manusia dengan Sang Pencipta, dengan kata lain sebagai upaya untuk mencapai ma'rifah ruhiyah. Dalam perjalanan spiritual ini manusia harus bisa menyerap asma Allah Tuhan semesta alam yang merupakan cerminan dari sifat-sifat-Nya. Pendidikan pesantren mengupayakan seseorang mendapatkan ilmu pengetahuan religius (agama) yang bertujuan agar 
Zainuddin Syarif, Manajemen Kepemimpinan Kiai dan Kontribusinya Terhadap Mutu Pendidikan Pesantren

manusia memperoleh akhlak yang terpuji. Proses belajar mengajar di pesantren bertujuan mengasah otak, maka agama berfungsi menyelaraskan akal dan hati secara proporsional, mengedepankan niat dan cita-cita, menyeimbangkan lahir dan batin. 


\section{DAFTAR PUSTAKA}

A. Mughni, Syafiq. 2002. Dinamika Intelektual Islam; Pada Abad Kegelapan", Surabaya: LPAM.

Azra, Azyumardi. 2000. Pendidikan Islam: Tradisidan Modernisasi menuju Millenium Baru, Jakarta: Logos Wacana Ilmu.

Baharun, Hasan. 2017 Total Moral Quality: A New Approach For Character Education In Pesantren " Ulumuna Journal of Islamic Studies Published by State Islamic Institute Mataram Vol. 21, No. 1

Dhofier, Zamahsyari. 1982. Tradisi Pesantren; Studi tentang Pandangan Hidup Kiai Jakarta: LP3ES.

Dubin, A.E 1991. The Principal as Chief Executive Officer London: The Falmer Press.

Harrison, R. dan G.R. Carrol, Desember 1991, Keeping The Faith: A Model of Cultural Transmission in Forma Organizations, Administrative Science Quartely.

Ismail, 2017. "Politik Pendidikan Islam di Daerah (Studi Kebijakan Pemerintah Provinsi Jawa Timur Dalam Pengembangan Madrasah Diniah)", (Ph. D. Diss., Pascasarjana Universitas Islam Negeri Sunan Ampel Surabaya),

Majid, Nurcholis 1995. Bilik-BilikPesantren: Sebuah Potret Perjalanan. Jakarta: Paramadina.

Permadi 1996. Pemimpin dan Kepemimpinan dalam Manajemen Jakarta: Rineka Cipta.

Pidarta, Made. 1988. Manajemen Pendidikan Indonesia, Jakarta: Bina Aksara.

Robbins , Stephen P. and Timoty A. Judge (2007). Organizational Behavior (New Jersey: Pearson Interntional Education).

Shate, Vijay 1982. Culture and Related Corporate Realistics, (Homewood: Illinois: Ricard D. Irwin, Inc.

Sigit, Suhardi. 2003. Prilaku Organisasional Common Understanding (Yogyakarta: BPFE-UTS) .

Syarif, Zainuddin. 2010. Dinamika politik Kiai, (Desertasi, IAIN Surabaya). 